\title{
UJI EFEKTIVITAS ANTIBAKTERI KOMBINASI EKSTRAK DAUN PALIASA (Kleinhovia hospita L) VARIETAS BUNGA PUTIH DAN BUNGA UNGU TERHADAP PERTUMBUHAN Staphylococcus aureus dan Escherichia coli
}

\author{
Rusli*)., Muliana Hafid $^{* *)}$, Novi Nugrayati Badjadji**) \\ ${ }^{*}$ Jurusan Farmasi Poltekkes Kemenkes Makassar \\ ${ }^{* *}$ Program Studi Farmasi Fakultas MIPA Universitas Pancasakti Makassar
}

\begin{abstract}
ABSTRAK
Penelitian ini bertujuan mengetahui kemampuan daya hambat Daun Paliasa (Kleinhovia hospita L) Varietas Bunga Putih Dan Bunga Ungu Terhadap Bakteri Staphylococcus aureus Dan Escherichia coli. Desain penelitian yang digunakan adalah eksperimental laboratorium yang dilaksanakan di Laboratorium Mikrobiologi Fakultas Matematika Dan Ilmu Pengetahuan Alam Universitas Hasanuddin Makassar. Penelitian ini menggunakan sampel daun paliasa bunga ungu, bunga putih, serta kombinasi daun paliasa bunga ungu : bunga putih dengan perbandingan 1:1, 1:2, dan 2:1. Hasil penelitian menunjukan terdapat adanya daya hambatan terhadap pertumbuhan bakteri Staphylococcus aureus Dan Escherichia coli. Setelah dilanjutkan dengan Uji Analisis Variasi dan Uji Beda Nyata Terkecil yang lebih efektif pada kombinasi 2:1 (bunga ungu : bunga putih).
\end{abstract}

Kata Kunci : Daun Paliasa (Kleinhovia hospita L), Daya Hambat, Staphylococcus aureus Dan Escherichia coli.

\section{PENDAHULUAN}

Tumbuhan telah lama digunakan oleh masyarakat Indonesia sebagai obat tradisional. Hasil dan manfaatnya telah dirasakan secara langsung sehingga penggunaan obat tradisional semakin meningkat. Penggunaan obat tradisional secara umum dinilai lebih aman dari pada penggunaan obat modern. Hal ini disebabkan karena obat tradisional memiliki efek samping yang relatif lebih sedikit daripada obat modern. Salah satu tumbuhan yang banyak digunakan oleh masyarakat Sulawesi Selatan sebagai obat tradisional adalah Paliasa (Alwy, 2010).

Daun paliasa (Kleinhovia hospita L) sudah lama digunakan oleh masyarakat Sulawesi Selatan untuk pengobatan penyakit seperti gangguan hati dan kanker. Sebutan paliasa ditemukan pada 3 jenis tumbuhan yang berbeda yaitu Kleinhovia hospita Linn, Melochia umbellata (Houtt) Stapf var. deglabrata, dan Melochia umbellata (Houtt) Stapf var. Visenia (Ridhay dkk, 2012). Paliasa (Kleinhovia hospita L), suku Sterculiaceae merupakan tumbuhan yang daunnya digunakan dan dipercaya berkhasiat sebagai obat yang mampu mengobati penyakit kuning (liver), hipertensi, diabetes dan kolesterol dengan cara meminum air rebusannya (Erwin dkk, 2009; Noor dkk,
2004; Raflizar dkk, 2006). Daun paliasa mengandung senyawa kimia alkaloid, asam prusid, minyak menguap (minyak atsiri), saponin, kardenolin, bufadienol dan antrakinon, terpenoid dan fenolik, terskopoletin, keampferol, quersetin, serta senyawa sianogenik (Ulfa, 2008). Penyakit infeksi merupakan penyakit yang banyak diderita oleh masyarakat Indonesia sejak dahulu. Menurut WHO, satu dari beberapa penyebab penyakit dan kematian disebabkan infeksi bakteri dan jamur (Dehghani dkk, 2012). Penyakit infeksi yang banyak diderita masyarakat diantaranya disebabkan karena Staphylococcus aureus, Escherichia coli, Salmonella typhi, Vibrio cholerae, Staphyolococcus aureus, Pseudomonas aeruginosa, dan sebagainya (Dzulkarnain $\mathrm{dkk}$, 2006). Penelusuran dan pemanfaatan senyawa aktif alami yang bersifat antibakteri didasarkan pada banyaknya bakteri patogen yang dapat menimbulkan masalah serius pada manusia. Penggunaan bahan-bahan kimia dan antibiotik yang tidak rasional dapat menyebabkan resistensi bakteri (Marpaung, 2004).

Staphylococcus aureus adalah bakteri Gram positif. Sel-sel berbentuk bola, berdiameter $0,5-1,5 \mu \mathrm{m}$, terdapat dalam 
tunggal dan berpasangan dan secara khas membelah diri pada lebih dari satu bidang sehingga membentuk gerombolan yang tak teratur, non motil, Tidak diketahui adanya stadium istirahat (Garrity, 2004).

Escherichia coli merupakan bakteri Gram negatif berbentuk batang lurus, 1,1 $1,5 \mu \mathrm{m} \times 2,0-6,0 \mu \mathrm{m}$, motil dengan flagellum peritrikum atau non motil. Tumbuh dengan mudah pada medium nutrien sederhana. Laktosa difermentasi oleh sebagaian besar galur dengan produksi asam dan gas (Pelczar et al, 2008).

Oleh karena itu, dilakukan penelitian ini untuk melihat hambatan pertumbuhan bakteri Staphylococcus aureus dan Escherichia coli pada kombinasi ekstrak daun paliasa (Kleinhovia hospita $\mathrm{L}$ ) varietas bunga putih dan bunga ungu. Tujuan dilakukannya kombinasi untuk melihat efek minimum maksimum antar varietas baik bunga putih maupun bunga ungu.

\section{Rumusan Masalah}

1. Apakah kombinasi ekstrak daun paliasa (Kleinhovia hospita L) varietas bunga putih dan bunga ungu dapat menghambat pertumbuhan bakteri Staphylococcus aureus dan Escherichia coli?

2. Pada kombinasi berapa ekstrak daun paliasa (Kleinhovia hospita L) varietas bunga putih dan bunga ungu dapat menghambat pertumbuhan bakteri Staphylococcus aureus dan Escherichia coli?

\section{Tujuan Penelitian}

1. Untuk mengetahui apakah kombinasi ekstrak daun paliasa (Kleinhovia hospita L) varietas bunga putih dan bunga ungu dapat menghambat pertumbuhan bakteri Staphylococcus aureus dan Escherichia coli.

2. Untuk mengetahui pada kombinasi berapa ekstrak daun paliasa (Kleinhovia hospita L) varietas bunga putih dan bunga ungu dapat menghambat pertumbuhan bakteri Staphylococcus aureus dan Escherichia coli.

\section{Manfaat Penelitian}

Manfaat penelitian ini adalah untuk mendapatkan data ilmiah mengenai manfaat ekstrak daun paliasa (Kleinhovia hospita L) varietas bunga putih dan bunga ungu dalam menghambat pertumbuhan bakteri Staphylococcus aureus dan Escherichia coli, dan juga penulis mendapatkan tambahan ilmu tentang daun paliasa sehingga dapat memberikan informasi kepada masyarakat mengenai manfaat dari tumbuhan daun paliasa (Kleinhovia hospita L).

\section{METODE DAN BAHAN \\ Alat dan Bahan}

Alat yang digunakan dalam penelitian ini antara lain autoklaf, aluminium foil, batang pengaduk, bunsen, cawan petri, corong, erlenmeyer, gelas ukur, gelas piala, inkubator, jangka sorong, kapas, laminar air flow, oven, ose bulat, pipet tetes, pinset, spoit, tabung reaksi, thermometer, dan timbangan analitik. Sedangkan Bahan yang digunakan dalam penelitian ini antara lain air suling, etanol 70\%, kertas $\mathrm{pH}$ universal, kultur murni Staphylococcus aureus, kultur murni Escherichia coli, medium Nutrien Agar (NA), dan ekstrak daun paliasa (Kleinhovia hospita L) varietas bunga putih dan bunga ungu.

\section{Lokasi dan Waktu Penelitian}

Penelitian ini dilaksanakan pada bulan Desember 2016 di Laboratorium Mikrobiologi Fakultas Matematika dan Ilmu Pengetahuan Alam Universitas Hasanudin.

\section{Populasi dan Sampel}

Populasi dalam penelitian ini adalah bakteri yang menyebabkan diare sedangkan sampel yang digunakan adalah bakteri Staphylococcus aureus dan Escherichia coli.

\section{Pengambilan Bahan Uji}

Bahan uji Daun Paliasa (Kleinhovia hospita L) diambil di Kelurahan Bungaya, Kecamatan Tamalate, Provinsi Sulawesi Selatan.

\section{Pengolahan Bahan Uji}

Daun paliasa dibersihkan dari kotoran dengan cara dicuci pada air mengalir, kemudian dikeringkan dengan cara diangin-anginkan dan terlindung dari sinar matahari langsung selama satu hari, setelah kering lalu dilakukan pengubahan 
bentuk dengan cara dipotong kecil-kecil, kemudian dikeringkan.

\section{Ekstraksi Bahan Uji}

Ditimbang masing-masing bahan uji daun paliasa (Kleinhovia hospita L) varietas bunga putih dan bunga ungu sebanyak 500 g pada timbangan analitik. Setelah itu dimasukkan masing-masing bahan uji kedalam wadah maserasi, kemudian ditambahkan masing-masing pelarut etanol $70 \%$ sampai bahan uji terendam. Dibiarkan selama 5 hari sambil diaduk berulang-ulang. Kemudian disaring hasil maserasi dengan kain flannel dan diperas, setelah itu dilanjutkan dengan dimasukkan kembali dalam wadah maserasi selama 10 hari dengan mengganti pelarut etanol $70 \%$ yang digunakan sebanyak 2 kali tiap 5 hari. Kemudian dipisahkan endapan lalu diuapkan menggunakan rotary evaporator hingga di peroleh ekstrak kental. Ekstrak kental yang di peroleh kemudian diuapkan kembali menggunakan water bath hingga di peroleh ekstrak kering. Hasil ekstraksi disimpan dalam wadah dan di tutup menggunakan aluminium foil.

\section{Pengujian Bahan Uji}

Pengujian ekstrak daun paliasa (Kleinhovia hospita L) varietas bunga putih dan bunga ungu dilakukan dengan metode difusi paper disk. Medium Nutrient Agar steril dicairkan, dimasukkan kedalam cawan petri kemudian dibiarkan memadat. Setelah itu dimasukkan swab steril kedalam tabung reaksi yang berisi suspensi bakteri uji lalu di inokulasikan diatas medium NA steril, di diamkan selama 15 menit. Setelah itu diletakkan 5 cakram kertas yang telah direndam larutan uji (ekstrak etanol daun paliasa varietas bunga putih dan bunga ungu) masing-masing 5 cakram untuk masing-masing bahan uji yaitu daun paliasa bunga putih, daun paliasa bunga ungu serta kombinasi dari daun paliasa varietas bunga putih : daun paliasa varietas bunga ungu di mana perbandingannya $1: 1,2: 1$, dan 1:2. Setelah itu di inkubasi pada suhu $37^{\circ} \mathrm{C}$ selama 1 x 24 jam dan kemudian diamati zona hambat yang terbentuk.

\section{Pengamatan dan Pengolahan Data}

Pengukuran dilakukan setelah $1 \mathrm{x}$ 24 jam masa inkubasi, kemudian inkubasi dilanjutkan 2 x 24 jam, diameter zona hambat diukur dengan menggunakan mistar geser. Hasil pengukuran dikumpulkan sebagai data, selanjutnya dilakukan pengolahan data secara statistik dengan uji anava dan dilanjutkan dengan uji Beda Nyata Terkecil (BNT). Setelah itu dilakukan pembahasan dan ditarik kesimpulan.

\section{HASIL DAN PEMBAHASAN}

\section{Hasil Penelitian}

Dari hasil penelitian dan pengamatan zona hambatan pada uji aktivitas daun paliasa ( Kleinhovia hospita $\mathrm{L}$ ) varietas bunga putih dan bunga ungu terhadap pertumbuhan Staphylococcus aureus dan Escherichia coli pada masa inkubasi 24 jam dengan suhu $37^{0} \mathrm{C}$ maka diperoleh hasil pengukuran yang dapat dilihat pada tabel di bawah ini.

Tabel 1. Hasil Pengukuran Diameter Zona Hambat Daun Paliasa (Kleinhovia hospita L) Varietas Bunga Putih Dan Bunga Ungu Terhadap Pertumbuhan Staphylococcus aureus Dan Escherichia coli Pada Masa Inkubasi 24 Jam Dengan Suhu $37^{\circ} \mathrm{C}$.

\begin{tabular}{|c|c|c|c|c|c|c|c|c|}
\hline \multirow[b]{2}{*}{ Bakteri Uji } & \multirow[b]{2}{*}{ Replikasi } & \multicolumn{5}{|c|}{ Diameter Zona Hambat ( $\mathrm{mm}$ ) } & \multirow[b]{2}{*}{ Total } & \multirow[b]{2}{*}{$\begin{array}{c}\text { Rata - } \\
\text { rata }\end{array}$} \\
\hline & & $\mathrm{U}$ & $\mathrm{P}$ & $\begin{aligned} \mathrm{U} & : \mathrm{P}(1 \\
& : 1)\end{aligned}$ & $\begin{aligned} \mathrm{U} & : \mathrm{P}(1 \\
& : 2)\end{aligned}$ & $\begin{aligned} \mathrm{U} & : \mathrm{P}(2 \\
& : 1)\end{aligned}$ & & \\
\hline \multirow{5}{*}{ Escherichia coli } & I & 11,2 & 11,38 & 10,18 & 10,43 & 12,68 & 55,87 & \\
\hline & II & 12,73 & 11,83 & 13,18 & 11,33 & 19,23 & 68,3 & \\
\hline & III & 11,83 & 11,93 & 11,83 & 11,18 & 20,33 & 67,1 & \\
\hline & Total & 35,76 & 35,14 & 35,19 & 32,94 & 52,24 & 191,27 & \\
\hline & Rata-rata & 11,92 & 11,71 & 11,73 & 10,98 & 17,41 & & 12,75 \\
\hline Staphylococcus & $\mathrm{I}$ & 9,83 & 9,48 & 10,98 & 12,6 & 15.68 & 58,57 & \\
\hline aureus & II & 11,43 & 12,83 & 11,03 & 16,48 & 12,33 & 64,1 & \\
\hline
\end{tabular}




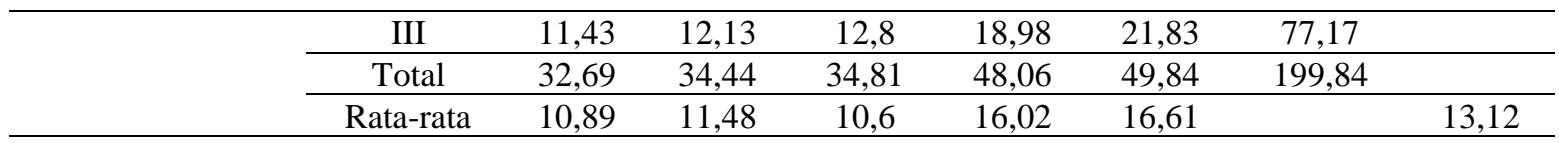

$\begin{array}{cl}\text { Keterangan } & \text { : Varietas Bunga Ungu } \\ \mathrm{U} & \text { : Varietas Bunga Putih } \\ \mathrm{P} & \text { : Varietas Bunga Ungu : Varietas Bunga Putih } \\ \mathrm{U}: \mathrm{P}(1: 1) & \text { : Varietas Bunga Ungu : Varietas Bunga Putih } \\ \mathrm{U}: \mathrm{P}(1: 2) & \text { : Varietas Bunga Ungu : Varietas Bunga Putih }\end{array}$

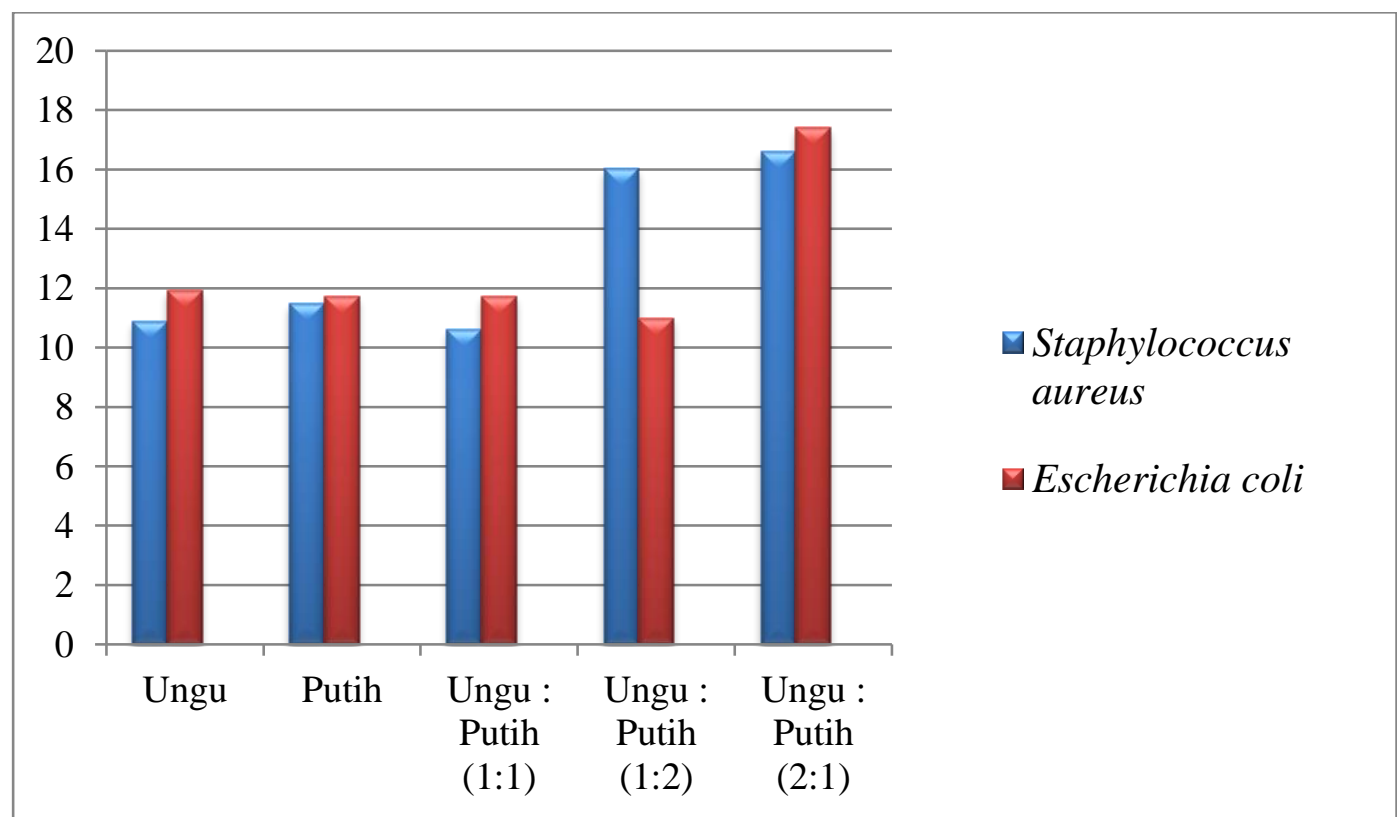

Gambar 1. Histogram Rata - rata Diameter Zona Hambat Daun Paliasa (Kleinhovia hospita L) Varietas Bunga Putih Dan Bunga Ungu Terhadap Pertumbuhan Staphylococcus aureus Dan Escherichia coli.

\section{Pembahasan}

Pada penelitian ini dilakukan untuk melihat efek dari aktivitas antibakteri dari kombinasi ekstrak etanol daun paliasa (Kleinhovia hospita L) varietas bunga putih dan bunga ungu terhadap pertumbuhan bakteri Staphylococcus aureus dan Escherichia coli dengan menggunakan metode difusi paper disk. Metode difusi paper disk merupakan metode yang paling banyak digunakan untuk menentukan kepekaan kuman terhadap antibiotik dan digunakan untuk melihat sensitivitas berbagai jenis mikroba terhadap antimikroba pada konsentrasi tertentu.

Tujuan dari kombinasi adalah untuk mengetahui efek minimum dan maksimum antar varietas baik bunga putih maupun bunga ungu terhadap pertumbuhan Staphylococcus aureus dan Escherichia coli.
Perbedaan besarnya daya hambat untuk masing-masing konsentrasi terhadap bakteri uji yaitu semakin tinggi konsentrasi semakin besar pula hambatannya, ini disebabkan adanya peningkatan senyawa aktif di dalam ekstrak atau cairan uji. Hal lain yang mempengaruhi difusi zat aktif adalah reaksi antara bahan aktif dan medium, viskositas medium dan temperatur inkubasi (Bornet, M.E, 1992).

Daun paliasa baik varietas bunga putih maupun varietas bunga ungu mempunyai kemampuan menghambat bakteri Staphylococcus aureus dan Escherichia coli. Hal ini disebabkan adanya senyawa antibakteri pada daun paliasa baik varietas bunga putih dan bunga ungu yang mampu menghambat pertumbuhan bakteri. Diduga kandungan senyawa daun paliasa yang mampu menghambat pertumbuhan 
Staphylococcus aureus dan Escherichia coli adalah alkaloid, tanin dan minyak atsiri.

Dari hasil yang diperoleh pada uji aktifitas antibakteri daun paliasa menunjukan bahwa diameter rata - rata zona bening pada bakteri Staphylococcus aureus yang mewakili gram positif lebih besar dibandingkan dengan diameter rata - rata zona bening pada bakteri Escherichia coli yang mewakili gram negatif. Dan dari hasil yang diperoleh bahwa daun paliasa bunga ungu lebih dominan menghambat pertumbuhan bakteri Escherichia coli sedangkan untuk daun paliasa bunga putih lebih dominan menghambat pertumbuhan bakteri Staphylococcus aureus. Perbedaan hasil hambatan dari masing - masing bakteri baik Staphylococcus aureus maupun Escherichia coli diduga karena perbedaan kadar dari kandungan senyawa daun paliasa baik varietas bunga putih maupun bunga ungu.

Setelah dilanjutkan masa inkubasi 2 x 24 jam zona hambatan yang terbentuk berubah dari bening menjadi keruh, ini berarti bahwa daun paliasa (Kleinhovia hospita L) baik varietas bunga putih maupun bunga ungu memiliki efek anti bakteri yang bersifat bakteriostatik (menghambat pertumbuhan bakteri). Hal ini sesuai dengan pendapat stevy S.A (2013) yang mengatakan bila zona hambat yang terjadi tetap setelah 24 jam menunjukan bahwa antimiktoba yang digunakan bersifat bakteriosid (senyawa dapat membunuh pertumbuhan bakteri), sedangkan bila 24 jam masa inkubasi zona hambat yang mula - mula bening menjadi keruh menunjukkan bahwa antimikroba tersebut bersifat bakteriostatik (menghambat pertumbuhan bakteri).

Menurut Priyatmoko W (2008) menjelaskan bahwa suatu antiboitik maupun antibakteri dikatakan mempunyai aktifitas terhadap bakteri jika mempunyai ketentuan kekuatan sebagai berikut, luas daerah hambatan $20 \mathrm{~mm}$ atau lebih masuk kategori sangan kuat, daerah hambatan antara $10-20$ mm termasuk kategori kuat, daerah hambatan 5-10 mm masuk kategori sedang dan daerah hambatan $5 \mathrm{~mm}$ atau kurang masuk kategori lemah.

Daya hambat daun paliasa (Kleinhovia hospita L) baik varietas bunga putih maupun bunga ungu dengan rata - rata diameter hambatan 13, $03 \mathrm{~mm}$ untuk
Staphylococcus aureus dan Escherichia coli $12,75 \mathrm{~mm}$. Menurut Priyatmoko W (2008) mengatakan bahwa diameter rata - rata dari daun paliasa (baik varietas bunga putih maupun bunga ungu termasuk kategori kuat dalam menghambat pertumbuhan bakteri, sedangkan berdasarkan analisis statistik menggunakan ANAVA pada Faktor Hitung sebesar 865,46 menunjukan bahwa dari hasil FH termasuk dalam kategori yang sangan kuat menghambat pertumbuhan bakteri dan sangat signifikan. Dari hasil menunjukan bahwa daun paliasa (Kleinhovia hospita $\mathrm{L}$ ) pada perbandingan $2: 1 \% \mathrm{~b} / \mathrm{v}$ (bunga ungu : bunga putih) daya hambatnya terhadap Staphylococcus aureus dan Escherichia coli lebih besar dibandingkan pada perbandingan yang lainnya.

\section{PENUTUP}

\section{Kesimpulan}

Dari hasil penelitian yang diperoleh maka dapat disimpulkan sebagai berikut :

1. Kombinasi ekstrak daun paliasa (Kleinhovia hospita L) varietas bunga putih dan bunga ungu bersifat bakteriostatik atau dapat menghambat pertumbuhan Staphylococcus aureus dan Escherichia coli.

2. Perbandingan zona hambat pada kombinasi 2 : 1 (bunga ungu : bunga putih) lebih besar menghambat Escherichia coli dibandingkan pada Staphylococcus aureus.

\section{Saran}

Untuk penelitian selanjutnya dapat dilakukan aktifitas antibakteri kombinasi ekstrak daun paliasa (Kleinhovia hospita L) varietas bunga putih dan bunga ungu terhadap bakteri patogen yang lain serta pengujian lanjut analisis KLT.

\section{DAFTAR PUSTAKA}

Alwy M.K. 2010. Pengaruh Pemberian Ekstrak Daun Paliasa (Kleinhovia hospital Linn.) Terhadap Pengidap HBs Ag Positif/VHB. Medical Journal Avicenna. Vol. 1. No. 01. hal. 2.

Dehghani, M., Ganjali, Z., Javadian, F., Estakhr, J. and Heidari, A. 2012. Anti-Microbial Activity of Ethanolic and Aqueous Extract of Cynanchum acutum. British 
Journal of Pharmacology and Toxicology Vol. 3(4): 177-180.

Dzulkarnain, B., Dian, S. dan Au, C. 2006. Tanaman Obat Bersifat Antibakteri di Indonesia. Cermin Dunia Kedokteran. No. 110; 35-47.

Erwin, Alfian N., Soekamto N.H., dan Harlim T. 2009. Skrining Bioaktivitas Beberapa Bagian Jaringan Tumbuhan Paliasa (Melochia umbellata (Hout) Stapf var. Degrabrata $K$ ). Indonesia Chimica Acta. Vol. 2. No.1. hal. 2.

Garrity. G. M., Bell. J. A. and Lilburn. T.G, 2004. Taxonomic Outline of The Prokaryotes Bergey's Manual of Systematic Bacteriologi, 2thEdition, United States of America, Springer, New York Berlin Hendelberg.

Marpaung, E.L. 2004. Flavonoid Dari Buah Sonneratia caseolaris Engl. Dan Kegunannya Sebagai Antibakterial : Studi Laboratorium Infeksi Vibrio Harveyi Pada Udang Windu, Penaeus monodon Fab. Tesis. Fakultas Perikanan Dan Kelautan, Institut Pertanian Bogor : Bogor.

Noor A., Kumanireng A.S., Kartikasari R., Suryaningsih, Hakim A., dan Takbir. R. . 2004. Isolasi dan Identifikasi Konstituen Organik Tanaman Daun Paliasa, Kleinhovia hospita Linn pada Kelarutan
Berdasarkan Kelompok Polaritasnya. Marina Chimica Acta. Vol. 5. No.2 hal. 2-10.

Pelczar. Michael J. and Chan. E.C.S. 2008. Dasar-Dasar Mikrobiologi. Terjemahan oleh Hadioetomo, Ratna sari dkk. Jakarta : Universitas Indonesia.

Raflizar, Adimunca C., dan Tuminah S. 2006. Dekok Daun Paliasa Kleinhovia hospita Linn Sebagai Obat Radang Hati Akut. Cermin Dunia Kedokteran. No 50. hal. 1014.

Ridhay, A., Noor, A., Soekamto, N.H., Harlim, T., dan Altena, I.V. 2012. A Stigmasterol Glycoside From The Root Wood of Melochia umbellata (Houtt) Stapf var. degrabrata K. Indo. J. Chem. Vol. 12 (1): $100-103$.

Ulfa M. 2008. Praskrining Bioaktivitas Ekstrak Kulit Batang Kleinhovia hospita Linn. Jurnal Penelitian UNRAM. Vol. 2. No.13. hal. 98-99.

Wiyatno, Y. 2010. Aktifitas Minyak Atsiri Kulit Batang Kayu Manis (Cinnamomun burnanii BI) Terhadap Staphylococcus aureus Dan Pseudomonas aureginosa Multiresisten Antibiotik. Skripsi Universitas Muhammadiyah Surakarta : $\quad$ Surakarta 